\title{
Reflexión histórica sobre el P. Las Casas en la obra de Miguel Ángel Asturias ${ }^{1}$
}

\author{
Hidefuji Someda ${ }^{2}$ \\ Universidad Kansai Gaidai, Japón \\ Universidad de Osaka, Japón
}

\begin{abstract}
resumen
Se descubre y analiza el perfil histórico y político de Bartolomé de Las Casas, según la configuración literaria que elabora Miguel Ángel Asturias en su obra teatral La audiencia de los confines. Mediante un cotejo de datos históricos, se examina la interpretación que ofrece el escritor guatemalteco del clérigo sevillano, en cuanto a su papel de reivindicador de los derechos de los indios, y de denunciador de los crímenes de parte de los conquistadores españoles.
\end{abstract}

\begin{abstract}
The historical and political profile of Bartolomé de Las Casas is discovered and analyzed, according to the literary configuration of Miguel Ángel Asturias in his play La audiencia de los confines. By verifying historical data, a description is provided of the interpretation of that Guatemalan author of the Sevillian priest, regarding his role in defending the rights of the indigenous peoples and in denouncing the crimes of the Spanish conquerors.
\end{abstract}

Palabras clave: Bartolomé de Las Casas, Miguel Ángel Asturias, teatro histórico, conquista de América

Keywords: Bartolomé de Las Casas, Miguel Ángel Asturias, historical drama, conquest of America

1 Ponencia presentada en el xx Congreso Internacional de Literatura Centroamericana (ciLca), 2012. Recibido: 30 de marzo de 2011; aceptado: 12 de julio de 2011.

2 Correo electrónico: h.someda@gmail.com; sitio web: <http://someda.jpn.org>. 
Desde la aparición en Madrid, a fines del siglo xvi, de la obra de Juan de Castellanos Elegías de varones ilustres de Indias, Fr. Bartolomé de Las Casas ha sido tratado en varias obras literarias por escritores hispanoamericanos. A lo largo del siglo xx, Las Casas sigue siendo un personaje histórico que ha cautivado a autores hispanoamericanos como Gabriela Mistral y Pablo Neruda (chilenos), Rodolfo Usigli y Emilio Pacheco (mejicanos), Luis A. Baralt (cubano), Enrique Buenaventura (colombiano), Ernesto Cardenal (nicaragüense) $)^{3}$. Es innegable que en tales producciones literarias - poesía, novela o teatro - el fraile sevillano se le representa casi sin excepción como una persona «sublime» que ya en una época temprana del nacimiento del Mundo Atlántico, o mejor dicho del sistema mundial de la Época Moderna, reprochó implacablemente la conquista española y defendió valientemente los derechos humanos y la capacidad cultural de los pueblos vencidos de las Indias; en una palabra, Las Casas ha sido apreciado y elogiado comúnmente como «Padre de América», «Apóstol de los indios», «Precursor del anticolonialismo», «Pionero de la Teología de la Liberación»o «Primer defensor de los derechos humanos».

Estos títulos le han sido otorgados de acuerdo con el modo que cada escritor tiene de ver la historia y la realidad de su propio país o del mundo hispanoamericano. Por ello cada escritor tiene su propio modo de acercamiento a Las Casas; lo que significa que mediante el análisis de la imagen de Las Casas presentada en las obras literarias podemos enterarnos de los problemas sociopolíticos, económicos o culturales en los espacios geográficos y temporales en que vive el autor. Pero eso no significa que todas las imágenes literarias de Las Casas tengan un sentido muy «local». Es decir que imágenes tales como la de «Defensor de los indios» o la de «Padre de América» sí están creadas de acuerdo con la historia de la conquista y la dominación españolas en las Indias, pero

3 Marcel Bataillon y Raymond Marcus, Etudes sur Bartolomé de Las Casas (París: Instituto de Estudios Hispánicos, 1966) 254-256. En Costa Rica el profesor Juan Durán Luzio publicó en 1992, Bartolomé de Las Casas ante la Conquista de América. Las voces del historiador (Heredia: EUNA). 
que, por ejemplo, la imagen de «Primer defensor de los derechos humanos» o la de «Precursor de la Teología de la Liberación» están basadas en la realidad histórica y presente de los oprimidos del mundo. Esta diferencia se debe fundamentalmente a la manera que el escritor tiene de interpretar el sentido histórico de las obras y actividades de Las Casas. En otras palabras, la imagen de Las Casas depende principalmente del modo interpretativo de cada autor sobre la experiencia vital y la actualidad de las doctrinas de LasCasas.

Ahora bien, vamos a dejar de lado a los escritores que tratan a Las Casas como una persona «perfecta», aceptando la imagen tradicional de Las Casas creada históricamente en Europa o en los Estados Unidos por los «hispanófobos» o los «pseudo-anticolonialistas», pero que al mismo tiempo y paradójicamente consideran humanitaria la política de la corona española, en especial del emperador Carlos V sobre los indios. Llaman la atención los autores que lo representan como un ser «histórico» de carne y hueso que lleva una pesada carga sobre las espaldas, teniendo en cuenta la transformación del modo de ser y de pensar de Las Casas y situándolo lo más exactamente posible en el contexto histórico en que estaban en marcha la conquista y la dominación españolas de las Indias. Como tales podemos citar a dos eminentes escritores centroamericanos: uno el poeta nicaragüense Ernesto Cardenal; el otro es el reconocido novelista, poeta y dramaturgo guatemalteco Miguel Ángel Asturias. Por el escaso tiempo de que dispongo, quisiera aclarar el sentido histórico de la imagen de Las Casas presentada por Miguel Ángel Asturias. Se trata de la obra teatral titulada La audiencia de los confines (1957) que consta de tres actos4.

Debo admitir que voy a analizar dicho drama histórico, no como especialista en literatura sino como historiador japonés que lleva dedicándose más de cuarenta años a la investigación de la actualidad de las obras y actividades del padre sevillano; y ello porque

4 Miguel Ángel Asturias, Teatro (Losada. Buenos Aires, 1964). 
no tengo capacidad de hacerlo de acuerdo con la metodología literaria, como lo hace Orbelina Polanco de Guzmán 5 .

Como el escritor es conocido mundialmente, no es necesario presentar su biografía, colmada de incidentes, por lo que quiero entrar en materia. Primero, veamos la imagen de Las Casas representada en la obra teatral de Asturias. Es una obra teatral de tema histórico que escribió el autor durante su permanencia temporal como exiliado en Buenos Aires (1957), y en ella se tratan la confusión y el desorden que la promulgación de las Leyes Nuevas de las Indias en 1542-1543 originó no sólo entre las autoridades coloniales y los pobladores españoles, sino también entre los eclesiásticos y los indígenas en la «muy noble y muy leal Ciudad de Santiago de los Caballeros de Guatemala». Bien, antes de analizar la imagen lascasiana de Asturias, escuchemos las palabras del autor mismo sobre la obra en cuestión:

El teatro me ha tentado siempre y últimamente escribí una obra, en efecto sobre Fray Bartolomé de las Casas...; esta obra tiene como personaje principal... a Las Casas. Lo tomo en el momento en que el gran obispo y verdadero Quijote vuelve de España a Indias después de haber triunfado sobre Sepúlveda, logrando que Carlos V decrete las Leyes de Indias, lo que permite crear un tribunal ante el que se administre justicia a los indígenas hasta entonces sometidos al capricho y a la voluntad de los conquistadores. Algunos de éstos, como es sabido, esperaban liquidar a Fray Bartolomé, y en este instante es cuando empieza la obra ${ }^{6}$.

Aquí se ve claramente que el guatemalteco aprecia en mucho a Las Casas como protagonista en la redacción de las Leyes Nuevas y pone de manifiesto la esperanza suscitada en la administración de la justicia para con los vencidos por parte de la Audiencia, alto organismo

5 Orbelina Polanco de Guzmán, La figura de Fray Bartolomé de Las Casas en La Audiencia de los confines, de Miguel Ángel Asturias (Guatemala: Universidad de San Carlos de Guatemala, 2007).

6 J. Corrales Egea, «Tres escritores hispanoamericanos en París II: Miguel Ángel Asturias», Insula, 197 (1963): 12 . 
político-judicial creado en las Indias. A pesar de esta afirmación del autor que acabamos de ver, como bien indica Bataillon ${ }^{7}$, la obra no reproduce fielmente el proceso histórico, o más bien podría decirse que el autor modificó audazmente los hechos históricos, es decir materiales, de la obra. Porque es en 1542 o 1543 cuando fueron promulgadas las Leyes Nuevas de las Indias, y es en 1544 cuando nuestro padre fue consagrado obispo de Chiapas. Además, sabemos que los artículos más importantes de dichas ordenanzas reales, referentes a las encomiendas y a la esclavización de los indígenas, fueron revocados por el emperador Carlos V en octubre de 1545, y que la famosa y candente controversia con Ginés de Sepúlveda en torno a la legitimidad de la conquista española tuvo lugar en Valladolid entre 1550 y 1551. Según Vallejo García-Hevia, estos llamados anacronismos, traslaciones y alteraciones espacio-temporales son característicos de la obra de Asturias ${ }^{8}$. Es decir, no se trata de ignorancia del autor sobre tales hechos históricos, sino de un procedimiento literario para perfilar más vivamente el contenido de la verdad.

Ello nos hace recordar la técnica del alemán Reinhold Schneider (1903-1958) en su novela histórica Las Casas ante Carlos V, El Padre de los indios (1937-38) cara a cara entre Las Casas y Ginés de Sepúlveda. No podemos afirmar con certeza que Asturias haya leído esta obra del poeta y escritor alemán, que consagró la vida a la resistencia contra el nazismo, pero tampoco podemos negarlo totalmente, ya que de igual modo que en la obra de Schneider desempeña un papel importante el personaje llamado «Bernardino», que es otro Las Casas, en la obra de Asturias también entra en escena un fraile llamado Jerónimo de la Cruz, quien no es más que otro Las Casas.

\footnotetext{
7 Marcel Bataillon, «Miguel Angel Asturias et Bartolomé de Las Casas», Europe 473 (1968): 6-10.

8 José María Vallejo García-Hevia (ed.), «Prólogo», en: Miguel Ángel Asturias, Las Casas, el Obispo de Dios: la audiencia de los confines. Crónica en tres andanzas (Madrid: Cátedra, 2007) 118.

9 Reinhold Schineider, El Padre de los Indios. Las Casas ante Carlos V (Buenos Aires: Ediciones Criterio, 1956).
} 
Los personajes principales de la obra, excepto Las Casas, son todos inventados por el autor y su mayoría es innominada, tales como el gobernador, el obispo, el deán, canónigo, mayoral y arcediano, aunque podemos adivinar con facilidad sus modelos, es decir, los personajes reales en la historia. Aunque Las Casas mismo no aparece más que en la tercera andanza de la obra, no sería error decir que el padre sevillano es protagonista de la obra, ya que el argumento de la misma se desarrolla en torno a las injusticias e iniquidades de los colonizadores y los gobernantes españoles, que se muestran categóricamente hostiles al padre dominico, quien no sólo desempeñó un papel importante en la redacción de las Leyes Nuevas que reglamentan la derogación gradual de las encomiendas, sino que también escribió un tratado en que prohibía a los religiosos confesar a los penitentes que tuvieran esclavizados a los indios. Bien, a continuación veamos brevemente el argumento del drama histórico en cuestión.

En la andanza primera, una doble escena es conjugada en el imaginario escenario de representación de la obra. A un lado se encuentra el despacho del gobernador español (identificado con Pedro de Alvarado) donde éste, con la ayuda del escribiente (Pedrales), escribe una carta al emperador Carlos V. La carta es copia de la famosa epístola que Fr. Toribio de Motolinía OFM., uno de los «Doce apóstoles» de México, envió al emperador con fecha de 2 de enero de 1552, condenando y calumniando violentamente a Las Casas. Y en su carta, el gobernador, que se define a sí mismo como amante de las doncellas indias ofrecidas a los dioses en sus prácticas religiosas, se opone a las Leyes Nuevas recién redactadas y defiende las encomiendas como una recompensa merecida para los conquistadores que ganaron con riesgo de su vida muchas tierras y muchos vasallos para la corona. El gobernador, entregado a la vida hedónica robando doncellas indias, manda capturar a un jefe guerrero llamado Musén-Ca, guardador de la miel de las doncellas y exige su rescate a losindios.

Mientras, al otro lado de la doble escena, en el fondo se levanta una pirámide del Dios del Maíz, donde está rezando una joven india 
llamada Ulú Kinich Ulú. Allí irrumpe un grupo de guerreros indígenas que se alzan en armas al enterarse del secuestro de Musén Ca. Y Naborí, hermosa india guerrera, llega a concertar un acuerdo con el gobernador y le ofrece una gran cantidad de oro como rescate por Musén-Ca, pero el gobernador no lo pone en libertad sino que pide insistentemente aun más oro como rescate. Además el gobernador traza el plan diabólico de atraer con engaño a las doncellas para violarlas.

Así, cuando el gobernador arregla mañosamente todo para apoderarse de Ulú Kinich Ulú, aparece en su despacho un padre dominico. El gobernador se atolondra, tomándole por Las Casas, pero pronto se tranquiliza al darse cuenta de su error. Pero el sacerdote, Fr. Jerónimo de la Cruz, le reprocha furiosamente su intriga y le exige liberar a Musén-Ca. El primer acto concluye con la escena en que el gobernador, al saber que los indios han descubierto su maliciosa conspiración y se han levantado en armas para recuperar a su jefe, ordena ajusticiar a Musén-Ca, y al mismo tiempo propone a Fr. Jerónimo, como punto del regateo para perdonar la vida de Musén-Ca y liberarlo, la pacificación del alzamiento de los indios y la entrega de los rebeldes.

En la andanza segunda, la acción se desarrolla en el palacio arzobispal y entran en escena el obispo de Guatemala (identificado con Francisco Marroquín), el gobernador y varios religiosos. A principios del segundo acto, por medio del diálogo entre los eclesiásticos mismos y del diálogo entre éstos y el gobernador, diálogos que versan principalmente sobre las Leyes Nuevas o de Las Casas, el autor aclara dos situaciones históricas muy importantes en la dominación española de las Indias. Una es la discordia entre los religiosos misioneros acerca de la Leyes Nuevas, y la otra, el conflicto entre las autoridades coloniales y las eclesiásticas en torno a la jurisdicción.

Ya Fr. Jerónimo de la Cruz, que se dirigió a las tierras de los rebeldes indios lacandones para su pacificación sin saber que MusénCa había sido ejecutado tras arrancarle la lengua, halló la muerte, siendo víctima de las flechas de los indios, quienes lo tomaron por 
robador de las doncellas. Ahora escuchemos el diálogo del Obispo con el gobernador en torno a la muerte de Fr. Jerónimo de la Cruz:

Obispo.- ¡En la muerte de fray Jerónimo no está muy claro que los indios hayan obrado por iniciativa propia!

Gobernador (sombrío).- ¿Vos lo creéis? ¿Tenéis alguna prueba?

Obispo.- Dominico, seguidor y secundador de las doctrinas de fray Bartolomé de Las Casas, qué de extraño suponer, por simple presunción humana, que los españoles de esta villa, a quienes perjudican las Leyes Nuevas por privarla de sus esclavos y heredamientos, le hubieran hecho asesinar. ¿No fueron los españoles los que asesinaron al obispo de León, Castilla de Oro?... (269-270) ${ }^{10}$

Y a continuación atendamos a su diálogo acerca de la muerte de Musén-Ca:

Obispo.- Se habla de un indio guerrero que dio u ofreció muchas onzas de oro en rescate de Musén-Ca, el que murió sin lengua, sin bautizo y sin confesión.

Gobernador (poniéndose de pie presa de indignación).- ¿Pero es que me estáis interrogando a mí? ¿Buscáis implicar españoles en un delito de indios? ¿Qué lucubráis? ¿Qué mancilla es ésta?... Habláis de Musén-Ca... habláis de un jefe guerrero...

Obispo (ya de pie, interrumpiendo).- ¿De un cacique? ¡De un monstruo, señor Gobernador, de un monstruo! ¡Ése fue el alma de la conspiración, tened seguro! (271-272)

Así, se insinúa la responsabilidad del gobernador en la muerte de Fray Jerónimo y de Musén-Ca, y se agudiza más y más el enfrentamiento entre el gobernador y el Obispo. Y cunde el desconcierto, tanto en el Palacio Arzobispal como en el del gobernador, ante la confusión y los conflictos de jurisdicciones. De este modo, el autor 10 Miguel Ángel_Asturias, Las Casas, el Obispo de Dios: la audiencia de los confines. Crónica en tres andanzas, edición de José María Vallejo García-Hevia (Madrid: Cátedra, 2007); en adelante los números de página de esta edición se indicarán entre paréntesis. 
indica perspicazmente la idiosincrasia de la conquista y la dominación españolas, equiparando la muerte del fraile con la del indio «infiel». Es decir que a través de la muerte de Fr. Jerónimo de la Cruz, misionero cristiano, y de la de Musén-Ca, idólatra infiel, Asturias nos transmite el mensaje de que la evangelización pacífica, doctrina principal de Las Casas, resulta totalmente incumplida debido a la conquista de los españoles llamados cristianos. Pero según el autor, esta situación no es irremediable ni inalterable, sino más bien provisional o temporal, ya que Asturias la muestra reversible y remediable al hacer entrar en escena al propio Las Casas en la tercera andanza.

Después de marcharse el gobernador muy enfadado del palacio arzobispal, empiezan los españoles a alborotarse con el rumor de la llegada de Las Casas a la ciudad. Todos ellos sin excepción tienen una fuerte animosidad contra el padre sevillano, ya que utiliza como arma apropiada para realizar la justicia social una práctica religiosa e individual de los creyentes cristianos, esto es: la confesión. Y también porque las alegaciones del padre dominico en contra de la conquista, la encomienda y la esclavización de los indios podrían llegar a destruir la base de la vida de los españoles en las Indias. Por lo tanto los pobladores españoles, pobres o ricos, le lanzan reproches violentos. Asturias pone de manifiesto la realidad despiadada e inhumana de la dominación española, por medio del grito desgarrador de un viejo conquistador, que grita: «iMis esclavos!... ¡Mis esclavos!... ¡Autoridad, hacienda, honra, comida y ser me quitan, si me quitan mis esclavos!... » (303-304).

Asturias presenta a Las Casas como una persona a quien sus coetáneos españoles temían mucho más que a Francis Drake, corsario inglés que por entonces aterrorizaba a la sociedad colonial de los españoles en las Indias. Con esta comparación el guatemalteco quiere señalar que Las Casas «atacó violentamente», más que nadie, la realidad de la conquista española, provocando en los españoles la pérdida no sólo de las riquezas materiales, sino también de las espirituales. 
El gobernador da a Naborí, que entra en escena en pos de él, la noticia falsa de que Musén-Ca fue ejecutado como instigador del levantamiento por las autoridades judiciales coloniales y que la recién fundada Audiencia de los confines les está buscando a él y a ella como responsables de la muerte de Fray Jerónimo de la Cruz. Intenta vengarse de los «malditos frailes» aprovechándose mañosamente de los tumultos de los encomenderos y los dueños de esclavos indios, tumultos originados por la noticia de la entrada de Las Casas en la ciudad, y convence con mentiras a Naborí de que para librarse de tan difícil situación no hay otro remedio que arrestar a Las Casas mediante una acción conjunta de españoles e indios. Así ambos toman juntos sus disposiciones para asaltar el palacio arzobispal y aprehender a Las Casas, con los españoles encabezados por el gobernador y los indios bajo el mando de Naborí, quien no sabiendo la verdad de la muerte de Musén-Ca, jura vengarse de ella.

El tercer y último acto empieza con un soliloquio de Las Casas en su celda en medio de las sombras; soliloquio que no es otra cosa que la reproducción literal de las doctrinas que él expuso en la famosa controversia con Ginés de Sepúlveda en Valladolid entre 1550 y 1551 . Durante su monólogo, desde el fondo de la escena, resuenan las maldiciones e imprecaciones lanzadas por los españoles contra Las Casas, y luego se desarrolla una discusión imaginaria, es decir que se entrecruzan violentamente las opiniones de Las Casas y los españoles en torno a las Leyes Nuevas de las Indias. Ellos le acusan de haber sido encomendero y promovido la introducción de los esclavos negros en las Indias. La presentación de tales hechos históricos, como declara el autor mismo, demuestra que Asturias ha investigado y averiguado de modo ferviente no sólo los documentos históricos, sino también los estudios o monografías de eminentes lascasistas, tal como el Dr. Lewis Hanke.

Cambiando el escenario, en el salón del palacio arzobispal Las Casas conversa con los religiosos, y conteniendo a aquellos que lo elogian mucho por haber desempeñado un importante papel en la 
redacción y promulgación de las Leyes Nuevas, reglamentos favorables para los indígenas, dice lo siguiente:

Mi papel fue el de un simple testigo. No hice sino decir al Rey: «Yo lo vide». ¡Todo lo que he hablado, todo lo que he escrito, lo « vide yo»! Pero los arquitectos de esta gloria son el juez y el que puso al juez. Son, Dios Nuestro Señor que puso al Rey y el Rey que hizo de supremo juez. A ellos, a ellos id y cantadles alabanzas por todo lo conseguido. (333)

Ante tales palabras, todos dicen a una voz: « «Un milagro!... ¡Fue un milagro!...». Aquí podemos percibir claramente la vaga esperanza que Asturias tiene en el cristianismo, considerando que es una religión capaz de realizar la justicia social. Dicha esperanza habría de dejar de ser un sueño imposible quizás con el nacimiento del movimiento llamado Teología de la Liberación en la década de 1960.

Nos encontramos ya en la escena en que los indios asaltan el palacio arzobispal. Ahí se desarrolla una discusión muy fuerte y violenta entre Naborí, Las Casas y los religiosos que intentan desesperadamente defenderlo. Naborí, enterada de todo, dice que quieren llevarse a Las Casas para defenderle de los españoles que le intentan matar, pero los religiosos que piensan que los indios mataron a Fr. Jerónimo de la Cruz, no pueden creer en las palabras de Naborí. Mientras tanto, empiezan los españoles a atacar el palacio, y Naborí aconseja a Las Casas darse a la fuga. Pero los religiosos piensan que los españoles son enviados de Dios para salvarles del ataque de los indios. En esta escena Asturias compara bien la actitud de Las Casas con la de los religiosos, ya mientras que Las Casas dirige una mirada cálida hacia los indios, los religiosos no pueden confiar más que en sus paisanos, es decir, los españoles. Podemos percatarnos de que Asturias insinúa que Las Casas es una persona solitaria: a diferencia de los religiosos que sí son capaces de llorar la muerte de los indios víctimas de la conquista, pero que no pueden ni quieren reflexionar 
sobre el sentido histórico de dicha tragedia provocada por el presunto objetivo sagrado de la salvación eterna, Las Casas se esforzó desesperadamente por encontrarse en la misma situación que se vieron obligados a sufrir los vencidos.

Naborí, dirigiéndose a Las Casas cuando éste se acerca a la puerta para persuadir a los españoles, grita: «iHuid!... ¡Ya no tenemos más!..! (Los españoles) ¡Vienen a mataros! (Fray Bartolomé va hacia la puerta de la izquierda con el rosario en alto. Suplicante.) ¡No lo entreguéis!... ¡Sois nuestra última esperanza!... ¡Es nuestro padre! » (344).

Entonces un disparo de arcabuz hiere en el pecho a Naborí, que se acercaba a Las Casas para arrancarle del peligro de ser asesinado. Naborí cae al suelo herida. En este instante sale a la escena el gobernador y declara que viene a arrestar a Las Casas. Después de unos instantes de silencio, Naborí, que está a punto de perder la vida, aclara a voz en cuello que el gobernador, a pesar de haber recibido como rescate mucha cantidad de oro, no liberó a Musén-Ca, sino que lo ejecutó, y que la muerte de Fr. Jerónimo de la Cruz se debe a una trampa de él. También manifiesta que el gobernador ha trazado la intriga de asesinar a Las Casas, $\mathrm{y}$ a tal efecto ha exigido a los indios la colaboración. Al oírlo, el gobernador intenta matar a Naborí, y Las Casas, conteniendo al gobernador, declara ante Naborí que en adelante, por las Leyes Nuevas recién promulgadas, los indios no serán esclavizados y disfrutarán todos de la libertad. Al escucharlo, Naborí se convierte al cristianismo y recibe el sacramento de la extremaunción. Mientras tanto el gobernador le echa varias maldiciones a Las Casas, luego aparecen los alguaciles diciendo: « iJusticia del Rey!... ¡Justicia del Rey!...» (49-350). Y con las palabras que la garnacha o juez lanza al gobernador: «iEn nombre de la Audiencia de los Confines, daos preso!» (351), cae el telón.

Asturias escribió esta obra teatral en 1957, cuando estaba expatriado en Argentina. El escritor sirvió de diplomático bajo el régimen democrático de Jacobo Arbenz, pero en 1954, cuando surgió 
el gobierno anticomunista de Castillo Armas, resultado del golpe de Estado de los militares que recibieron ayuda del gobierno estadounidense, dimitió del cargo y se exilió en Buenos Aires. Durante su exilio, Asturias publicó una tras otras las novelas político-sociales, llamadas indigenistas, como El Papa Verde (1954), Week-end en Guatemala (1956) y Los ojos enterrados (1960), y criticó febrilmente el neocolonialismo y el colonialismo doméstico. Para Asturias, la conexión entre la literatura y la política tiene otro sentido diferente del «engagement» del filósofo francés Sartre, que se divulgó en la Europa de la segunda mitad del siglo xx. Asturias explica la conexión entre política y literatura como sigue:

Coloco ese compromiso (literario-político) en el terreno del testimonio, la denuncia y la protesta, buscando plantear los problemas del hombre en relación con la vida, la muerte, la libertad. El latinoamericano es un autor invadido por los sucesos de la realidad circundante. Si quisiera estar en su torre de marfil lo sacaría de ella nuestra tremenda realidad, nuestros problemas vitales: seres humanos descalzos, hambrientos, sin todo. Esto no se puede callar, y la denuncia adquiere por eso una significación política... Ni la inmensa mayoría de los escritores latinoamericanos, ni yo en particular, somos agitadores políticos. Si nuestras obras adquieren a veces una significación política es por las circunstancias mismas del momento histórico en que vivimos... Hoy, la opresión política y la injusticia social siguen constituyendo en algunas partes un desafío que el intelectual no puede eludir sin evadir su responsabilidad de servicio público. La protesta del escritor va dirigida contra las injusticias, sufrimientos de su pueblo. Pero hay una razón más: en tanto que el escritor se rebela contra el ultraje que toda forma de opresión o de imperialismo representa para la cultura, la sensibilidad y la forma de vida de un pueblo ${ }^{11}$.

11 Miguel Ángel Asturias, Latinoamérica y otros ensayos, 2.da ed. (Madrid: Guadiana de Publicaciones, 1970) 18-19. 
Así entendía Asturias que el escritor europeo, emancipado de lo telúrico y de lo mitológico tras muchos siglos de civilización, podía dedicarse a explorar en su literatura «los problemas complejos de la psicología individual». No ocurría lo mismo con el narrador hispanoamericano, que todavía estaba encadenado, en aquel Nuevo Mundo, al infierno verde de la naturaleza y la humanidad americanas $^{12}$. En otras palabras, para Asturias los escritores de América Latina tienen la responsabilidad de desafiar las opresiones políticas y las injusticias sociales, crónicamente extendidas en la región, y resistir a los actos de destrucción sobre las culturas vernáculas. Asturias confía en la potencialidad de «la pluma» y la utiliza para cumplir dicha responsabilidad. Pero no para en eso, sino más bien que, como bien indica su accidentada vida, se ofrece a llevar a cabo con su propio ejemplo la justicia social.

Es natural que Asturias sintiese profunda simpatía por Las Casas, que en el siglo xvi (es decir, en la infancia del imperialismo moderno crecido junto con el capitalismo) se enfrentó a las circunstancias históricas en que eran miserablemente atropellados los derechos humanos de los indios, y luchó solo, con la palabra de Dios, contra ellas para defender la libertad y la vida de los naturales. Así, no sería erróneo afirmar que Asturias no es más que un nuevo Las Casas o, como él mismo lo define, un Quijote. Como se puede conjeturar con facilidad de las palabras de Asturias de que «siglos después de muerto, el obispo de Chiapas sigue todavía vivo», Las Casas y Asturias son coetáneos. Mientras aquél llegó a ser una persona imperecedera como testigo ocular de la destrucción de las Indias y su denunciador, Asturias consideró una obligación insoslayable de los intelectuales de la América Latina contemporánea aclarar y denunciar la realidad del neocolonialismo y el colonialismo doméstico, la política dictatorial y las injusticias sociales que están atormentando a los pueblos latinoamericanos.

12 Vallejo García-Hevia en Asturias (2007) 84-85. 
En resumen, en el drama histórico de la Audiencia de los confines, si la vemos como una obra literaria de resistencia, se notan tres intenciones principales: (1) la protesta contra la discriminación y la persecución de la raza del bronce y la reivindicación de sus derechos humanos, (2) el develamiento y la denuncia del mal y el crimen de la conquista no sólo militar, sino de la espiritual, y (3) la aclaración de la posibilidad de salvación del mal y del crimen. Tomemos un ejemplo: al final de la obra, la valiente guerrillera Naborí, en trance de muerte se convirtió al cristianismo, diciendo a Las Casas: «Creo en tu Dios». Es decir que el Dios que Naborí llegó a aceptar no es el Dios en que creían los españoles que se daban a las crueldades y atrocidades, sino el de quien Las Casas es fiel servidor. Debemos recordar que Las Casas había sido encomendero; es decir, que había tenido indios en su encomienda en las islas Antillas y había propuesto a la corona la introducción de negros esclavos en las Indias como mano de obra, para reemplazar a los indios corporalmente débiles. Así, Las Casas tenía un pasado de errores y pecados, pero pudo conseguir la salvación eterna y se convirtió en verdadero cristiano, verdadero religioso y verdadero apóstol de las Indias. Del mismo modo, Asturias señala que aunque se viva en el pecado, quien se da cuenta de ello y se arrepiente tiene la posibilidad de alcanzar la salvación eterna.

Para terminar, quisiera referirme otra vez a la obra de Schneider. Aunque he mencionado al principio que no puede afirmarse con seguridad que Asturias haya leído su corta novela histórica Las Casas ante Carlos v, considerando el hecho de que Schneider la escribió y publicó en unas circunstancias muy difíciles y agobiantes para los antinazistas como él, no es aventurero afirmar que Asturias tuvo oportunidad de leerla y experimentar profunda simpatía hacia el autor o su novela, ya que la primera versión española de la obra salió a luz en 1956 en Buenos Aires, donde vivía como expatriado. Hay ciertas coincidencias interesantes entre las dos obras en cuestión. Mientras Asturias compuso la obra teatral histórica superponiendo la conquista española del siglo xvi a la dictadura de Guatemala 
contemporánea, Schneider, uno de los refugiados internos, que resistió valientemente la política racista e inhumana de la Alemania nazi, escribió la novela traslapando la España conquistadora del siglo xvi con la Alemania contemporánea. Otra similitud entre ambas obras: en la obra de Asturias casi todos los personajes salen innominados, pero en la tercera andanza sale un negro llamado «Comacho» como inseparable sirviente de Las Casas (234, 236, 242-244); también en la novela de Schneider hay un personaje de nombre «Comacho» quien, aunque no negro sino indio, es el sirviente y ayudante de Las Casas. De ahí que es posible ver una relación estrecha entre las dos obras, aunque está de más decir que para asegurarlo es necesario realizar las minuciosas investigaciones bibliográficas. Sin embargo, podríamos afirmar que al igual que la imagen de Las Casas de Schneider la heredó el poeta alemán Hans Magnus Enzensberger («Las Casas, o una mirada retrospectiva hacia el futuro» 1969), en Centroamérica la imagen lascasiana de Asturias vive en la obra de Ernesto Cardenal, El estrecho dudoso ${ }^{13}$.

13 Ernesto Cardenal, El estrecho dudoso (Madrid: Ediciones Cultura Hispánica, 1966). 